\title{
Whole-body Vibratory Response Study Using a Nonlinear Multi-body Model of Seat-occupant System with Viscoelastic Flexible Polyurethane Foam
}

\author{
Gauri JOSHI ${ }^{1}$, Anil K. BAJAJ ${ }^{1 *}$ and Patricia DAVIES ${ }^{1}$ \\ ${ }^{1}$ Ray W. Herrick Laboratories, School of Mechanical Engineering, Purdue University, 585 Purdue Mall, West \\ Lafayette, IN 47907-2031, USA
}

Received July 2, 2009 and accepted June 29, 2010

\begin{abstract}
Vehicle occupants are exposed to low frequency vibrations with possible harmful effects such as mild discomfort, lower back pain, and even injury to the spine. Occupational drivers and operators of heavy machinery are exposed to significantly longer duration and higher levels of vibration. Thus, the modeling and prediction of biodynamic response of seated occupants to such vibrations is very important. Since the properties of seating foam affect the response of the occupant, there is need for good models of seat-occupant systems through which the effects of foam properties on the dynamic response can be directly evaluated. A nonlinear planar seat-occupant model which incorporates the nonlinear viscoelastic behavior of seating foam has been developed. This model is used to study response of the occupant to harmonic excitation applied at the seat base, in terms of the frequency response in vertical and fore-and-aft directions, the deflection shapes at resonance, as well as the seat-to-head-transmissibility. In addition, to better understand the role of flexible polyurethane foam in characterizing the system behavior, the response of a single-degree-of-freedom foam-block system is also studied. The effects of different masses riding on the foam block and undergoing vertical vibrations at different acceleration levels are also investigated.
\end{abstract}

Key words: Nonlinear multi-body model, Viscoelastic foam model, Dynamic response, Whole-body vibration, Seat-to-head transmissibility

\section{Introduction}

The drivers and occupants of vehicles are exposed to significant levels of low frequency vibrations due to the irregular road surfaces, vehicle suspension dynamics, as well as the excitation generated by vehicle engine dynamics. These vibrations can have a variety of effects on the occupants, ranging from mild discomfort to acute lower back pain due to loading of the spine, spinal injury, and interference with work efficiency, safety, and health. Thus, it is necessary to keep these vibrations transmitted to the occupant to a minimum, and to avoid exciting the various resonance frequencies associated with the body. Much work has been done over the years to study the biodynamic response of the human body to low frequency vibrations. These include significant experimental works that have measured transfer functions between the vibrations experienced at various critical locations on the occupant's body to the seat base vibrations, and other measures such as the seat-to-head transmissibility, dynamic resonances, static as well as dynamic pressure distributions, and apparent mass of the occupant ${ }^{1,2}$. Results and understanding

*To whom correspondence should be addressed.

E-mail: bajaj@purdue.edu developed based on these studies have helped in the development of a number of analytical or computational models that describe the human response to vertical excitations or whole body vibrations.

There are mainly three types of models for seat-occupant systems, these being based on the modeling technique used: lumped parameter models, multi-body models, and finite-element models. Lumped parameter models are popular in the description of vibratory response to vertical excitations. Most models are limited to linear uni-directional (vertical) response ${ }^{3)}$, though nonlinear models have also been proposed ${ }^{4)}$. Multibody models can be used in more than one dimension and are able to predict quantities/responses that cannot be measured, as against lumped parameter models. Also, they are able to describe the effects of global deformations with high computational efficiency as compared to finite-element models and do not need as many inputs. Despite their advantages, multibody models, especially in more than one dimension, have not been used widely, though there are a few models described in the literature, such as those developed by Nishiyama ${ }^{5-7)}$ Cho and Yoon ${ }^{8)}$, Kim et al. ${ }^{9)}$, Matsumoto and Griffin ${ }^{10)}$, Yoshimura et al. ${ }^{11)}$, Valentini and Vita ${ }^{12)}$, Teng et al. ${ }^{13)}$, and Verver et $a l^{14,15)}$. The dynamic response of a seated human is affected by a number of conditions, such as hand position ${ }^{16,17)}$, pos- 
ture $^{17-19)}$, foot support ${ }^{16,17)}$, position of the occupant, and most importantly, back support ${ }^{17-19)}$. The contribution of backrest in the human response to vibration is significant, as observed by Rakheja et $a l^{20)}$. From these results, it is seen that the presence of a backrest increases the amplitude of the seat-to-head transmissibility and the apparent mass, while also increasing the resonance frequency.

The seat characteristics also play an important role in the response of the seated occupants to vibrations. Most modern car seats are full-foam (flexible polyurethane foam), thus the properties of foam significantly affect the static and dynamic comfort of occupants. Hence, it is important to develop models of seat-occupant systems that incorporate the properties of the foam. Though there are a number of studies which measure the response of humans in seated position to excitation applied to the base of a rigid seat, only in the past few years have researchers started measuring and modeling the response to humans seated on soft seats, thus introducing the effects of the seating foam. The study by Hinz et al. ${ }^{21)}$ deals with the measurement of the apparent mass of human subjects on a soft seat with a backrest cushion, while the study by Patten et $a l .{ }^{22)}$ involves measuring and modeling the response of a human seated on an automotive seat cushion with a singledegree-of-freedom model. Cho and Yoon ${ }^{8)}$ use a multi-body model to describe the measured transmissibilities with backrest support.

The goal of this research is to develop a grounds-up and rational modeling approach that can predict the response of the seated occupant to various changing occupant and seat characteristics such as the weight or inertia distribution, posture, seatback angle etc. Such models will have the capability of predicting the static and dynamic response of the seated occupant in a unified manner. More specifically, these models will be able to predict the biodynamic response of seated occupants to low-frequency excitations applied at the seat base or introduced through the seat backrest. This approach builds on the two-dimensional, multi-body seat-occupant model developed previously by Ippili et al. ${ }^{23)}$ and Puri24) for predicting the static equilibrium position of the occupant in a car seat. The modeling approach incorporates rigid body dynamics of the occupant, large deformation viscoelastic models of the flexible polyurethane foam in unidirectional compression, a model of the forces at the seat-occupant interface, and the interaction of the occupant with the footrest. The profile of the occupant and that of the foam in the seat bottom as well as the seat back are also important contributors to the support provided to the occupant and are thus included in the model. The foam at the seat back and seat bottom is represented by a number of unidirectional nonlinear viscoelastic elements (or springs). The resulting multi-degree-of-freedom system's analytical model is developed using a constrained Lagrangian formulation. We should note that the proposed modeling framework is consistent with the automobile seat comfort development process put forward recently by Kolich ${ }^{25)}$.

Since flexible polyurethane foam is highly nonlinear and has viscoelastic characteristics, its effects on the complex dynamic response of the seat-occupant system can be more easily appreciated by first considering a single degree-offreedom 'foam-block' system where the block mass is constrained to unidirectional motion. This system was introduced by White $e t a l .^{26)}$ to help identify parameters of the nonlinear viscoelastic spring model of foam at different levels of excitation through nonlinear harmonic response based techniques (also see Singh et al. ${ }^{27)}$ ). Other techniques based on impulse response modeling (Singh et al. ${ }^{28)}$ ) and fractional derivative modeling of dissipation in foam (Deng et al. ${ }^{29)}$ ) have also been explored. It was seen in these studies that, contrary to expectation, the identified foam model parameters vary with the riding mass as well as the amplitude of excitation. In the present work, the nonlinear viscoelastic model parameters for foam are directly identified through unidirectional material testing, and this model is incorporated in the 'foam-block' system. The response of the resulting 'foam-block' system is studied for different riding masses and harmonic base excitation of different acceleration levels. With this understanding, the dynamic response of the complete seat-occupant model to harmonic base excitation with different acceleration levels is then studied through direct time integration.

\section{Seat-Occupant System and Mathematical Model}

The polyurethane foam in car seat back and seat bottom are assumed to be represented by a number of equivalent nonlinear viscoelastic spring and damper elements, as mentioned earlier. The parameters of these springs (or spring constants) depend on the properties of the seating foam, and are defined by the constitutive model of the foam as described below.

\section{Constitutive foam model}

Flexible polyurethane foam, which is used in automotive seating, exhibits nonlinear as well as viscoelastic behavior. The stress-strain relationship is highly nonlinear and depends on the strain rate, as seen from the stress-strain curve of foam obtained from a uniaxial cyclic compression test (Fig. 1). Here, a $76.2 \mathrm{~mm}$ (3 in) cube of a typical open-cell foam block was first compressed at a constant rate and then uncompressed

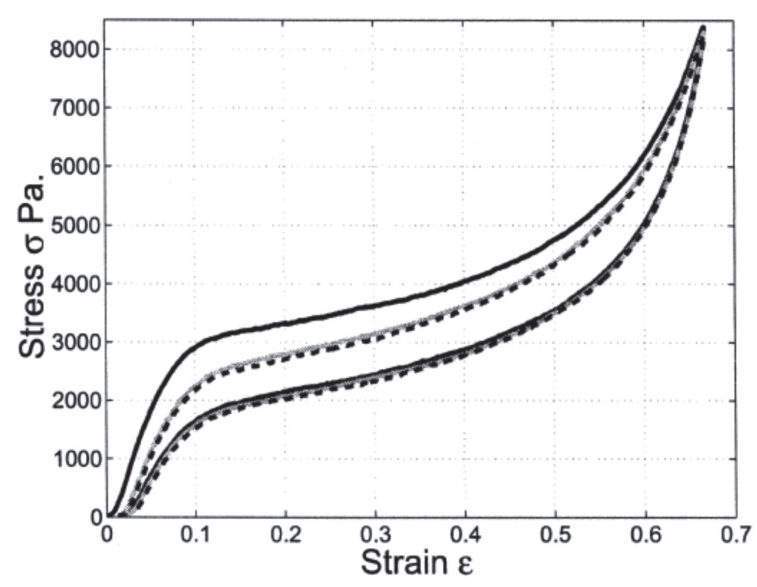

Fig. 1. Stress-strain response of flexible polyurethane foam to a cyclic compression test.

The foam block is compressed at a uniform rate from zero to $66.7 \%$ compressive strain, and then decompressed to zero strain. The strain rate for this test is $0.0043(\mathrm{~s})^{-1}$. The solid black curve - first cycle; the solid gray curve - second cycle; and the dashed black curve - third cycle. 
at the same rate. The foam was subjected to three consecutive cycles. Thus, the properties of foam depend on the compression in the foam, because the stiffness (or local slope of the stress-strain curve) of foam changes with compression level. Also, there is a substantial difference in the loading and unloading curves; this is due to the viscoelasticity and other dissipation mechanisms present in foam.

The model of the behavior of foam in unidirectional compression (for a single-cycle test) is assumed to be given by the following stress-strain relation:

$\sum_{j=1}^{M} k_{j} \varepsilon^{j}+\int_{0}^{t} \sum_{i=1}^{N} a_{i} e^{-\alpha_{i}(t-\tau)} \dot{\varepsilon}(\tau) d \tau=F(t) / A$

The first term represents the nonlinear elastic stress component, with the nonlinear form defined by a polynomial through 'stiffness' parameters $\left(k_{j}\right)$, while the second term is the viscoelastic stress component dependent on the strain rate, with $a_{i}$, $\alpha_{i}$ being the viscoelastic parameters. The symbol $F(t)$ represents the force acting on the foam, $A$ is the area of the foam normal to the direction of loading, and $\varepsilon$ is the strain in the foam. If the uncompressed height of the foam block is $H$ and the deformed height is $x$, the strain $\varepsilon$ is defined as $\varepsilon=\frac{H-x}{H}$. This formulation for the constitutive model of foam is based on the model structure introduced by White et al. ${ }^{26)}$, Singh et $a l .{ }^{27,28)}$ and Ippili et $a l .{ }^{23)}$ and was used by Puri ${ }^{24)}$ for the prediction of the static equilibrium of a seated occupant.

The material parameters $\left(k_{j}, a_{i}, \alpha_{i}\right)$ are estimated from the experimental data in the form of a stress-strain curve. The two-stage parameter estimation technique used by Puri ${ }^{24)}$ involves nonlinear optimization and linear least squares. The unloading part of the stress-strain curve is subtracted from the loading part of the curve. The resulting experimental stress difference is fitted to the viscoelastic part of model (1) using nonlinear least-squares. The reconstructed viscoelastic part is then subtracted from experimental stress data and the nonlinear elastic model is fitted to this using linear least-squares. The material parameters obtained by Puri ${ }^{24)}$ from the data taken in a $152 \mathrm{~s}(2.53 \mathrm{~min})$ single cycle test on a $76.2 \mathrm{~mm}$ cube of foam used in a commercial car seat are given in Table 1 .

The constitutive foam model is used as a building block for developing the seat-occupant system. The seating foam is assumed to be made up of a sufficient number of these nonlinear viscoelastic spring elements. This is a grounds-up approach to modeling the behavior of the seat-occupant system, where the material properties are an integral part of the model and the influence of changes in the material behavior on the occupant responses can be directly examined using this model. In this sense, this model is based on physical modeling of the components, and not a response-driven model.

\section{Seat-occupant model}

The seated occupant used in the present study is the mannequin in Ray W. Herrick Laboratories, and it was also used in previous studies of White et al. ${ }^{26)}$, Ippili et al. ${ }^{23)}$ and Puri24). A schematic of the mannequin is shown in Fig. 2 and its geometric and dimensional variables are defined in Fig. 3. The occupant is modeled by three rigid elements: $\mathrm{AB}$, the torso, $\mathrm{BC}$, the femur, and $\mathrm{CD}$, the shin. Their centers of mass are at $G_{1}, G_{2}$ and $G_{3}$, respectively. Point B is the hip-joint location (H-Point). The rigid components are connected by pin joints while the shin end D remains in contact with the foot
Table 1. The estimated nonlinear elastic and linear viscoelastic parameters for the seating foam. These values are used in the simulations for the single-degree-of-freedom 'foam-block' system and for the seat-occupant system

\begin{tabular}{cc}
\hline Parameter & Value \\
\hline $\mathrm{k}_{1}\left(N / \mathrm{m}^{2}\right)$ & $2.43 \times 10^{4}$ \\
$\mathrm{k}_{2}\left(\mathrm{~N} / \mathrm{m}^{2}\right)$ & $4.24 \times 10^{5}$ \\
$\mathrm{k}_{3}\left(\mathrm{~N} / \mathrm{m}^{2}\right)$ & $-8.17 \times 10^{6}$ \\
$\mathrm{k}_{4}\left(\mathrm{~N} / \mathrm{m}^{2}\right)$ & $5.90 \times 10^{7}$ \\
$\mathrm{k}_{5}\left(\mathrm{~N} / \mathrm{m}^{2}\right)$ & $-2.32 \times 10^{8}$ \\
$\mathrm{k}_{6}\left(\mathrm{~N} / \mathrm{m}^{2}\right)$ & $5.39 \times 10^{8}$ \\
$\mathrm{k}_{7}\left(\mathrm{~N} / \mathrm{m}^{2}\right)$ & $-7.39 \times 10^{8}$ \\
$\mathrm{k}_{8}\left(\mathrm{~N} / \mathrm{m}^{2}\right)$ & $5.54 \times 10^{8}$ \\
$\mathrm{k}_{9}\left(\mathrm{~N} / \mathrm{m}^{2}\right)$ & $-1.75 \times 10^{8}$ \\
$a_{1}\left(\mathrm{~N} / \mathrm{m}^{2}\right)$ & $3.26 \times 10^{4}$ \\
$\alpha_{1}\left(\mathrm{~s}^{-1}\right)$ & 0.419 \\
$a_{2}\left(\mathrm{~N} / \mathrm{m}^{2}\right)$ & $-1.16 \times 10^{3}$ \\
$\alpha_{2}\left(\mathrm{~s}^{-1}\right)$ & 0.1026 \\
\hline
\end{tabular}

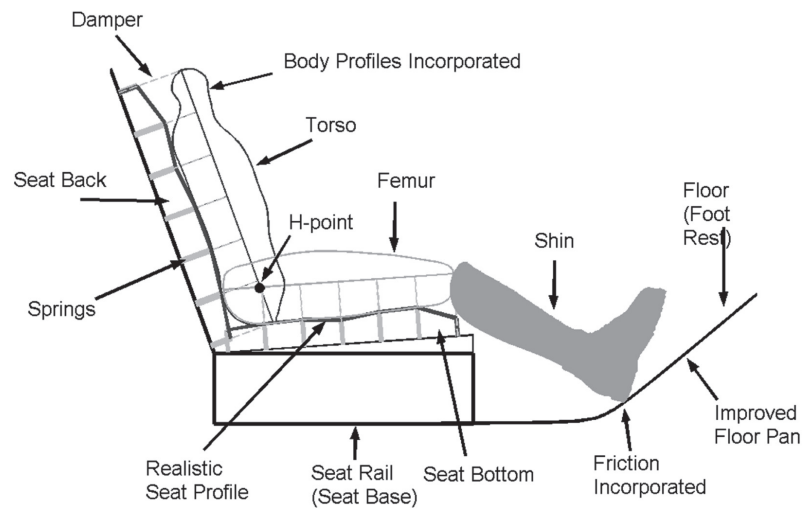

Fig. 2. The schematic with component characteristics for the seat-mannequin model.

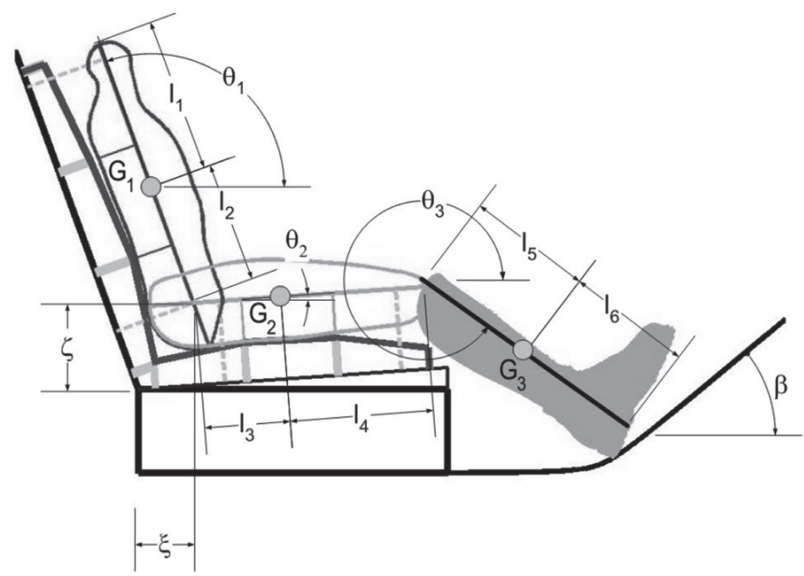

Fig. 3. The geometric variables that define the seat-mannequin model system. 
rest. The motion of the seat-occupant system can be defined by five generalized coordinates: $\xi$, horizontal displacement of the hip joint; $\zeta$, vertical displacement of the hip joint; $\theta_{1}$, angular displacement of the torso; $\theta_{2}$, angular displacement of the femur; and $\theta_{3}$, angular displacement of the shin. We should note that this modeling approach was motivated by Nishiyama's (Nishiyama ${ }^{5-7)}$ ) modeling efforts for vehicle-seatoccupant systems, generalizing his models to incorporate nonlinear viscoelastic behavior of seating foam as well as friction at the seat-occupant interface.

Some other features of this model are:

(a) The profile of the occupant is incorporated as it influences the contact between the seat and the occupant.

(b) The spring elements are assumed to be attached to the occupant and are constrained to remain perpendicular to the body. The seat back and seat bottom are represented by many nonlinear viscoelastic spring-damper combinations each, distributed equally along the back and bottom. In the current study, 7 springs each are used to represent the foam at the seat bottom and seat back.

(c) The in-plane forces at the seat-occupant interface are included in the model. It is assumed here that these forces act on the occupant tangentially at the points where the viscoelastic spring forces act normally. Thus, the force at a given point on the interface is $F_{\text {int }}=-\mu \mid F_{\text {spring }} \mathrm{l}$. This model represents the maximum friction force, and the orientation of each interface force is then always parallel to occupant's body. Two different coefficients of friction were used in the model, $\mu_{1}$ for seat back and $\mu_{2}$ for the seat bottom. The foot is constrained to slide along the foot-rest, and the friction at the foot-floor interface is also included.

(d) There is no dissipation or resistance at the joints of the occupant, all dissipation being modeled through the viscoelastic foam model and linear dampers associated with each nonlinear viscoelastic spring.

Profiles of the occupant torso, femur and shin

A detailed discussion of the method used to obtain the profiles of the occupant (mannequin) torso, femur and shin is given in Puri24). An overview of the methodology used is given here:

(a) A digital picture of the object whose 2D profile is to be generated is captured by placing it against a black background.

(b) The color photograph is converted into a black and white image.

(c) Using an edge detection routine (e.g. in MATLAB) the edge of the object is extracted.

(d) The extracted edge is scaled according to the actual dimensions of the object.

(e) The extracted edge is partitioned into different regions so that the edge in each partition can be represented mathematically by a polynomial.

\section{Equations of motion}

The derivation of the equations of motion of the seat-occupant system is given in detail in Ippili et al. ${ }^{23)}$ and Puri ${ }^{24)}$. A constrained Lagrangian formulation ${ }^{30}$ ) is used to derive the equations of motion of the system. The geometric (or holonomic) constraint on motion arises because the foot has to always move along the foot rest. The addition of the seat base excitation in the vertical direction to the system adds an extra generalized coordinate. The integro-differential algebraic equations given by Ippili et al. ${ }^{23)}$ and Puri ${ }^{24)}$ are slightly altered due to this addition.

For a system with $n$ generalized coordinates and $m$ constraints, the equations of motion are given by

$\frac{d}{d t}\left(\frac{\partial T}{\partial q_{r}^{\prime}}\right)-\frac{\partial T}{\partial q_{r}}+\frac{\partial U}{\partial q_{r}}+f_{r}^{c}=Q_{r}, \quad r=1,2, \ldots n$

where $T\left(q_{r}, q_{r}^{\prime}\right)$ is the kinetic energy, $U\left(q_{r}\right)$ is the potential energy associated with gravity as well as the elastic component of the forces in the viscoelastic springs, $Q_{r}\left(q_{r}, q_{r}^{\prime}, t\right)$ represent the generalized forces that cannot be derived via a scalar potential function (including $\mathrm{F}_{\mathrm{v}}$, the viscoelastic components of foam forces), and $q_{r}$ is a generalized coordinate. Furthermore, $f_{r}^{c}$ represents the constraint forces introduced due to the holonomic constraints on motion.

Let the $m$ constraints be of the form

$\phi_{j}\left(q_{1}, q_{2}, \ldots q_{n}\right)=0, \quad j=1,2, \ldots . ., m$

Then, the corresponding constraint forces are given by

$f_{r}^{c}=\sum_{j=1}^{m} \lambda_{j} \frac{\partial \phi_{j}}{\partial q_{r}}=\sum_{j=1}^{m} \lambda_{j} B_{r j}^{T}$,

where $B_{r j}^{T}=\frac{\partial \phi_{j}}{\partial q_{r}}$ and $\lambda_{\mathrm{j}}$ 's are the Lagrange Multipliers. The resulting equations (2) and (3) represent a system of $(n+m)$ integro-differential-algebraic equations. This system can be transformed to a differential-algebraic system with the introduction of new state variables in the following manner. First consider the viscoelastic force defined in equation (1). Let

$\sigma_{v}(t)=\int_{0}^{t} \sum_{i=1}^{N} a_{i} e^{-\alpha_{i}(t-\tau)} \dot{\varepsilon}(\tau) d \tau$

where $\sigma_{v}(\mathrm{t})$ represents the viscoelastic component of stress. The viscoelastic force is then:

Force $_{\text {viscoelastic }}=A \sigma_{v}(t)$

This can be used to derive an Nth order differential equation for the stress $\sigma_{v}(\mathrm{t})$. For a system with $\mathrm{N}=2$, that is, when the relaxation behavior associated with the viscoelastic force has two exponential terms, $\sigma_{v}(\mathrm{t})$ is easily shown to be the solution of the second-order differential equation:

$\ddot{\sigma}_{v}(t)=\left(a_{1} \alpha_{2}+a_{2} \alpha_{1}\right) \dot{\varepsilon}+\left(a_{1}+a_{2}\right) \ddot{\varepsilon}-\alpha_{1} \alpha_{2} \sigma_{v}-\left(\alpha_{1}+\alpha_{2}\right) \dot{\sigma}_{v}$

In this way, $N$ first-order differential equations are introduced to replace the integral terms in the model for each of the viscoelastic springs, $N$ being the number of exponentials in the viscoelastic behavior representation. Thus, the differentialalgebraic equations (DAE) for the seat-occupant system involving only one constraint have the form:

$[M]\{\ddot{q}\}+\{B\}^{T} \lambda=\{Q\}$

More explicitly, the equations of motion for the seat-occupant system with vertical base excitation $z(t)$ take the form: 


$$
\left[\begin{array}{cccccc}
M_{1} & 0 & A_{1} & A_{2} & A_{3} & 0 \\
0 & M_{1} & B_{1} & B_{2} & B_{3} & M_{1} \\
C_{1} & C_{2} & M_{7} & 0 & 0 & M_{2} \cos \theta_{1} \\
D_{1} & D_{2} & 0 & M_{8} & D_{3} & \left(M_{3}+M_{4}\right) \cos \theta_{2} \\
E_{1} & E_{2} & 0 & E_{3} & M_{9} & M_{5} \cos \theta_{3} \\
0 & 0 & 0 & 0 & 0 & 1 \\
0 & 0 & 0 & 0 & 0 & 0
\end{array}\right]\left[\begin{array}{c}
\ddot{\xi} \\
\ddot{\zeta} \\
\ddot{\theta}_{1} \\
\ddot{\theta}_{2} \\
\ddot{\theta}_{3} \\
\ddot{z}
\end{array}\right]=\left[\begin{array}{c}
-A_{4} \\
-B_{4} \\
-C_{3} \\
-D_{4} \\
-E_{4} \\
-\omega^{2} z \\
\phi
\end{array}\right]-\{B\}^{T} \lambda
$$

where the matrix elements are

$$
\begin{aligned}
& A_{1}=-M_{2} \sin \theta_{1}, A_{2}=-\left(M_{3}+M_{4}\right) \sin \theta_{2}, A_{3}=-M_{5} \sin \theta_{3}, \\
& B_{1}=M_{2} \cos \theta_{1}, B_{2}=\left(M_{3}+M_{4}\right) \cos \theta_{2}, B_{3}=M_{5} \cos \theta_{3}, \\
& C_{1}=-M_{2} \sin \theta_{1}, C_{2}=M_{2} \cos \theta_{1}, \\
& D_{1}=-\left(M_{3}+M_{4}\right) \sin \theta_{2}, D_{2}=\left(M_{3}+M_{4}\right) \cos \theta_{2}, D_{3}=M_{6} \cos \left(\theta_{2}-\theta_{3}\right), \\
& E_{1}=-M_{5} \sin \theta_{3}, E_{2}=M_{5} \cos \theta_{3}, E_{3}=M_{6} \cos \left(\theta_{2}-\theta_{3}\right) .
\end{aligned}
$$

The Jacobian matrix $\{B\}$ of the constraint is given by:

$$
\begin{aligned}
& \{B\}=\left\{B_{11}, B_{21}, B_{31}, B_{41}, B_{51}, B_{61}\right\}, \\
& B_{11}=-1, \\
& B_{21}=\frac{a \sin (\beta)}{\left(l_{q}+\zeta+\left(l_{3}+l_{4}\right) \sin \left(\theta_{2}\right)+\left(l_{5}+l_{6}\right) \sin \left(\theta_{3}\right)\right)^{2}}+\cot (\beta), \\
& B_{31}=0, \\
& B_{41}=\frac{a \sin (\beta)\left(l_{3}+l_{4}\right) \cos \left(\theta_{2}\right)}{\left(l_{q}+\zeta+\left(l_{3}+l_{4}\right) \sin \left(\theta_{2}\right)+\left(l_{5}+l_{6}\right) \sin \left(\theta_{3}\right)\right)^{2}}+\left(l_{3}+l_{4}\right) \cos \left(\theta_{2}\right) \cot (\beta)+\left(l_{3}+l_{4}\right) \sin \left(\theta_{2}\right), \\
& B_{51}=\frac{a \sin (\beta)\left(l_{5}+l_{6}\right) \cos \left(\theta_{3}\right)}{\left(l_{q}+\zeta+\left(l_{3}+l_{4}\right) \sin \left(\theta_{2}\right)+\left(l_{5}+l_{6}\right) \sin \left(\theta_{3}\right)\right)^{2}}+\left(l_{5}+l_{6}\right) \cos \left(\theta_{3}\right) \cot (\beta)+\left(l_{5}+l_{6}\right) \sin \left(\theta_{3}\right), \\
& B_{61}=0 .
\end{aligned}
$$

This is a vector here because there is only one constraint. The variables on the right side of the equations of motion are given by:

$A_{4}=-M_{2} \cos \theta_{1}-\left(M_{3}+M_{4}\right) \dot{\theta}_{2}^{2} \cos \theta_{2}+M_{5} \dot{\theta}_{3}^{2} \cos \theta_{3}+\Delta_{\xi}-\cos \theta_{1}\left(\sum_{i=1}^{7} F_{\text {bainti }}\right)+\cos \theta_{2}\left(\sum_{i=1}^{7} F_{\text {boint }}\right)$,

$B_{4}=-M_{2} \sin \theta_{1}-\left(M_{3}+M_{4}\right) \dot{\theta}_{2}^{2} \sin \theta_{2}+M_{5} \dot{\theta}_{3}^{2} \sin \theta_{3}+M_{1} g+\Delta_{\zeta}-\sin \theta_{1}\left(\sum_{i=1}^{7} F_{\text {baint } i}\right)+\sin \theta_{2}\left(\sum_{i=1}^{7} F_{\text {boint } i}\right)$,

$C_{3}=M_{2} g+\Delta_{\theta_{1}}$,

$D_{4}=M_{6} \dot{\theta}_{3}^{2} \sin \left(\theta_{2}-\theta_{3}\right)+\left(M_{3}+M_{4}\right) g \cos \theta_{2}+\Delta_{\theta 2}$,

$E_{4}=M_{6} \dot{\theta}_{3}^{2} \sin \left(\theta_{3}-\theta_{2}\right)+M_{5} g \cos \theta_{3}$

Note that the floor pan on which the foot slides has been modeled as a hyperbola. The equation for imposing this constraint is given by ${ }^{24)}$ :

$\phi=-a \frac{\sin (\beta)}{y_{f}}+y_{f} \cot (\beta)-x_{f}$,

$a=l_{o} / 1285.57$,

$x_{f}=-l_{o}+\xi(t)+\left(l_{3}+l_{4}\right) \cos \left(\theta_{2}(t)\right)+\left(l_{5}+l_{6}\right) \cos \left(\theta_{3}(t)\right)$,

$y_{f}=l_{q}+\zeta(t)+\left(l_{3}+l_{4}\right) \sin \left(\theta_{2}(t)\right)+\left(l_{5}+l_{6}\right) \sin \left(\theta_{3}(t)\right)$.

Here, $F_{\text {bainti }}$ and $F_{\text {boint } i}$ represent forces at the interface in the seat back and seat bottom respectively. The $\Delta$-terms describe the forces applied by the nonlinear and viscoelastic springs and the dashpots. Their complete expressions are given by:

$$
\begin{array}{rlrl}
\Delta_{\xi} & =\sum_{i=1}^{14} F\left(\delta_{i}\right) \frac{\partial \delta_{i}}{\partial \xi}+\sum_{i=1}^{14} c \dot{\delta}_{i} \frac{\partial \dot{\delta}_{i}}{\partial \dot{\xi}}, & \Delta_{\zeta}=\sum_{i=1}^{14} F\left(\delta_{i}\right) \frac{\partial \delta_{i}}{\partial \zeta}+\sum_{i=1}^{14} c \dot{\delta}_{i} \frac{\partial \dot{\delta}_{i}}{\partial \dot{\zeta}} \\
\Delta_{\theta_{1}}=\sum_{i=1}^{14} F\left(\delta_{i}\right) \frac{\partial \delta_{i}}{\partial \theta_{1}}+\sum_{i=1}^{14} c \dot{\delta}_{i} \frac{\partial \dot{\delta}_{i}}{\partial \dot{\theta}_{1}}, & \Delta_{\theta 2}=\sum_{i=1}^{14} F\left(\delta_{i}\right) \frac{\partial \delta_{i}}{\partial \theta_{2}}+\sum_{i=1}^{14} c \dot{\delta}_{i} \frac{\partial \dot{\delta}_{i}}{\partial \dot{\theta}_{2}}
\end{array}
$$

where $F\left(\delta_{i}\right)$ is the total (nonlinear elastic and viscoelastic) force in the $i^{\text {th }}$ spring.

The mass parameters are defined by:

$$
\begin{aligned}
& M_{1}=m_{1}+m_{2}+m_{3}, \quad M_{2}=m_{1} l_{2}, \quad M_{3}=m_{2} l_{3}, \\
& M_{4}=m_{3}\left(l_{3}+l_{4}\right), \quad M_{5}=m_{3} l_{5}, \quad M_{6}=m_{3} l_{5}\left(l_{3}+l_{4}\right), \\
& M_{7}=m_{1} l_{2}^{2}+I_{1}, \quad M_{8}=m_{2} l_{3}^{2}+m_{3}\left(l_{3}+l_{4}\right)^{2}+I_{2}, \quad M_{9}=m_{3} l_{5}^{2}+I_{3} .
\end{aligned}
$$

The geometric properties $\left(l_{i}\right)$ and inertial properties $\left(m_{i}, I_{i}\right)$ of the mannequin system are defined in Table 2 along with their numerical values used in simulations. In addition to the six equations given in equation (9), there are 14 second-order differential equations corresponding to the viscoelastic forces (similar to equation (7)) in the springs that have to be solved.

\section{Single-degree-of-freedom foam-block model}

As already indicated, the aim of this work is to study the response of the seat-occupant system to base excitation, where the system model incorporates constitutive model of flexible polyurethane foam. However, to gain a better understanding of the influence of the foam parameters on the response, a single-degree-of-freedom foam-block system is studied first. A schematic of the foam-block system and its representation as a mass-spring-damper system is shown in Fig. 4. The physical system consists of a foam cube with a metallic mass on top, which is constrained to move in the vertical direction by four vertical guide posts. The block on the foam cube produces compression in the foam. This setup can be represented as a mass-spring-damper system, where the spring element really represents the nonlinear viscoelastic spring, and the damper element accounts for additional damping in the foam not modeled by the viscoelastic element, and the friction at the vertical posts.

The equation of motion for the foam-block system with base excitation is:

$m \ddot{x}+c \dot{x}+A\left(\sum_{j=1}^{M} k_{j} \varepsilon^{j}+\int_{0}^{t} \sum_{i=1}^{N} a_{i} e^{-\alpha_{i}(t-\tau)} \dot{\varepsilon}(\tau) d \tau\right)$

$=-m \ddot{z}-m g$

Here, $x$ is the relative displacement of the mass, $z$ is the absolute displacement of the base, $\varepsilon$ is the strain produced due to the deformation in the foam and $A$ is the cross-sectional area of the foam cube represented by the spring.

This equation is used to study the frequency response of the foam-block system to base excitation. The material parameters used in this equation are the values obtained by applying system identification techniques to the $152 \mathrm{~s}$ (2.53 min) compression test data, and are given in Table 1 . 
Table 2. Seat parameter values and the inertial properties of the seat occupant (mannequin) used in simulations of the seat-occupant system

\begin{tabular}{lcc}
\hline Parameter & Symbol & Value \\
\hline Angle of seat base $\left(^{\circ}\right)$ & $\beta$ & 40.0 \\
Angle of seat back $\left(^{\circ}\right)$ & $\theta_{s}$ & 110.0 \\
Angle of seat bottom $\left(^{\circ}\right)$ & $\alpha$ & 4.0 \\
Distance from seat corner to base of foot $(m)$ & $l_{q}$ & 0.899 \\
Distance from seat base to seat cushion $(m)$ & $l_{q}$ & 0.163 \\
Number of springs and dampers at seat bottom & $w$ & 7 \\
Number of springs and dampers at seat back & $r$ & 7 \\
Damper constants $(N \mathrm{~s} / \mathrm{m})$ & $c_{1, \ldots, 14}$ & 40 \\
Contact area at the seat back $\left(\mathrm{m}^{2}\right)$ & & $6.9677 \times 10^{-2}$ \\
Contact area at seat bottom $\left(\mathrm{m}^{2}\right)$ & & $11.6129 \times 10^{-2}$ \\
Friction coefficient at the foot-floor interface & $\mu_{f}$ & 0.25 \\
Friction coefficient at the torso-seat interface & $\mu_{b a c k}$ & 0.25 \\
Friction coeffcient at the femur-seat interface & $\mu_{b o t t o m}$ & 0.25 \\
Mass of torso, neck, pelvis and arms $\left(\mathrm{kg}^{2}\right)$ & $m_{1}$ & 34.138 \\
Mass of femur $(\mathrm{kg})$ & $m_{2}$ & 17.844 \\
Mass of shin $(\mathrm{kg})$ & $m_{3}$ & 7.948 \\
Mass moment of inertia of torso, neck, pelvis and arms $\left(\mathrm{kgm}^{2}\right)$ & $I_{1}$ & 1.3927 \\
Mass moment of inertia of femur $\left(\mathrm{kgm}^{2}\right)$ & $I_{2}$ & 0.3352 \\
Mass moment of inertia of shin $\left(\mathrm{kgm}^{2}\right)$ & $I_{3}$ & 0.1973 \\
Length of torso and pelvis $(m)$ & & 0.6223 \\
Length of femur $(m)$ & & 0.5334 \\
Length of shin $(m)$ & & 0.4572 \\
\hline
\end{tabular}
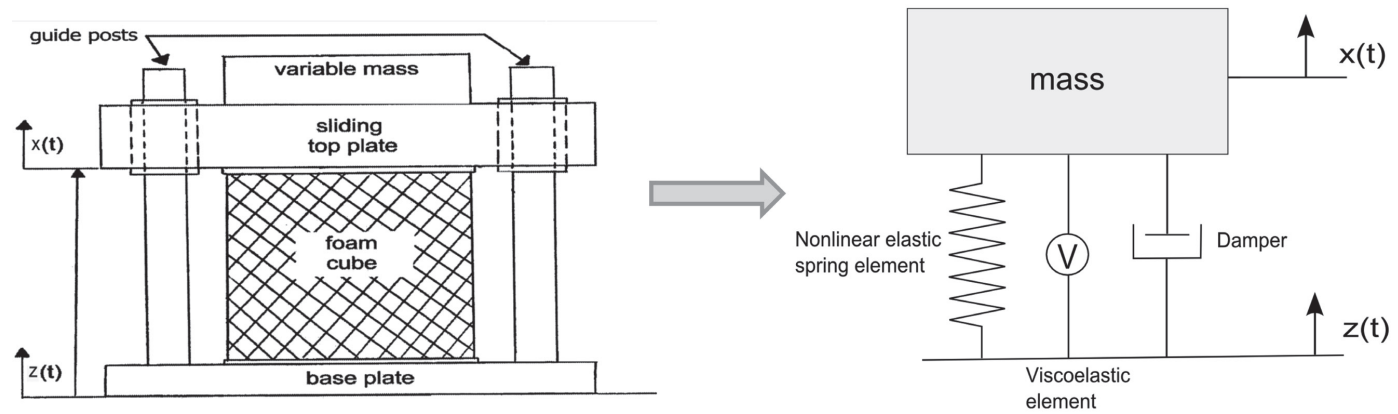

Fig. 4. Schematic of the single-degree-of-freedom 'foam-block' system.

\section{Methodology for Simulation of the Systems and Calculating their Frequency Responses}

The proposed methodology for modeling and simulation of seat-mannequin systems is described in Fig. 5. The first step, described above, is the development of the form of the model and then the choice of parameter values for the models. Key decisions in the foam model form are: the order of the nonlinear elastic polynomial model, $M$, and the number of viscoelastic terms $\left(a_{i}, \alpha_{i}\right)$ to be included in the model. The form of the model and the parameters in the foam model are estimated from compression tests on the $76.2 \mathrm{~mm}$ cube foam blocks. In the study here, the polynomial was chosen to be of order 9 and two terms were included in the viscoelastic model. For the seat-occupant system, the seat bottom and back each were modeled with 7 equi-spaced nonlinear viscoelastic springdamper elements and the coefficients of friction (both static and dynamic) at all interfaces needed to be determined or assumed.

In the occupant model described above and used in the following simulations, the head is removed. This was because the experimental mannequin's neck joint tended to become loose during experiments and the intent of the overall research here is to eventually compare experimental results with simulations. Incorporating the head into the occupant model is straightforward and would introduce and additional coordinate (rotation at the neck). In the work of Kim et $a l .{ }^{31}$ ), the seat back was allowed to rotate as well, and a torsional spring was introduced at the base of the seat; this was not included here. This degree of freedom is also straightforward to introduce. It was observed in experiments (Kim et $a l .{ }^{31)}$ ) that the seat back did rotate about the pin joint and that affected the seatoccupant system's modes of vibration. This degree of freedom will be incorporated in a future work on the model. 


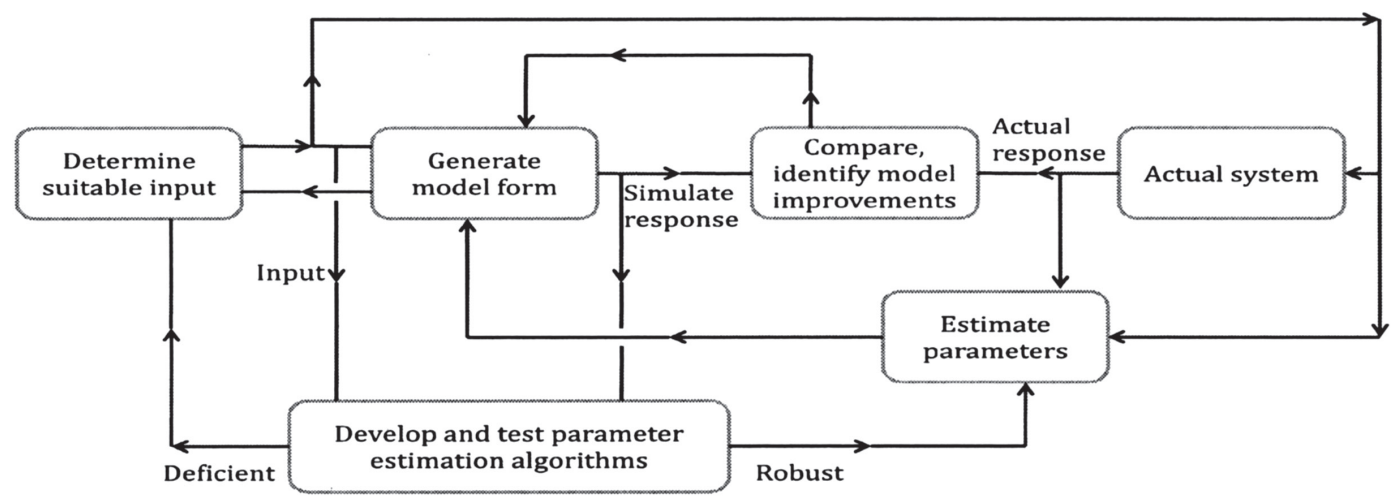

(a)

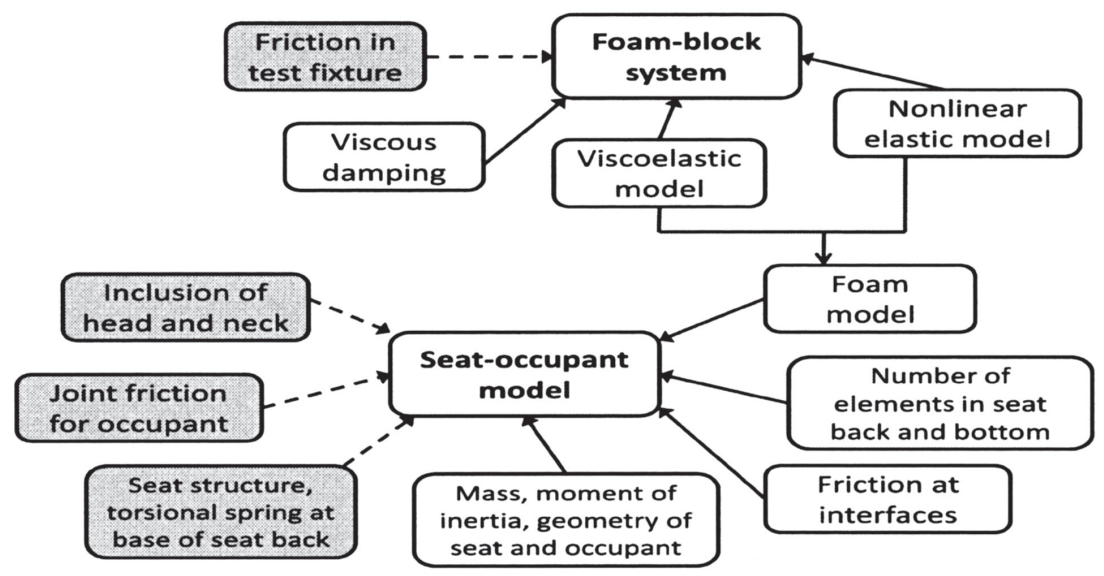

(b)

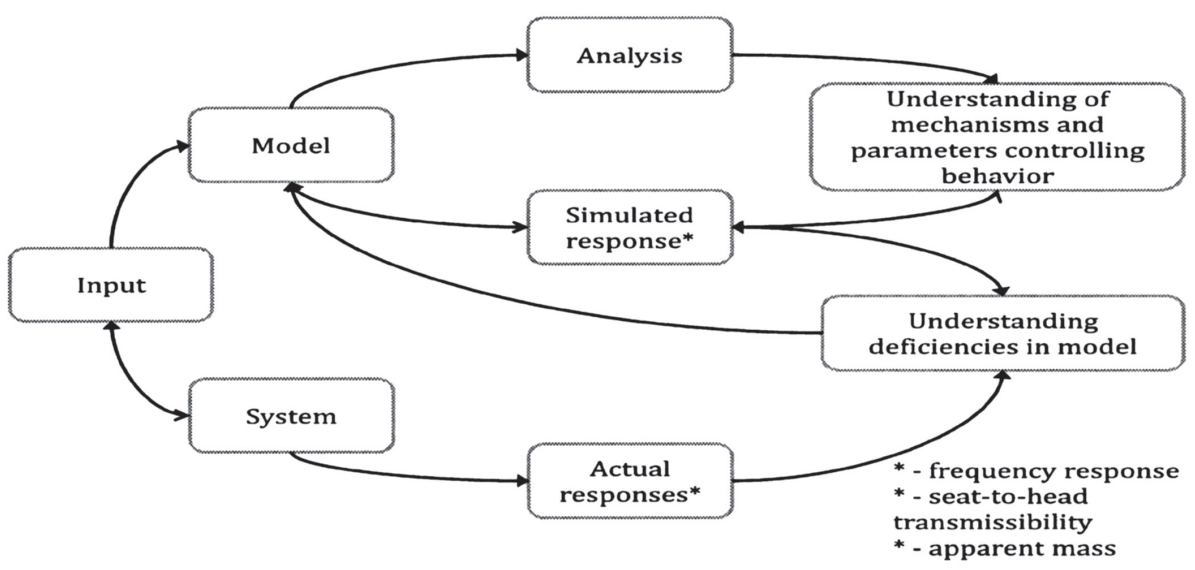

(c)

Fig. 5. Flowchart of methodology for simulation of the seat-occupant systems and for calculating their frequency responses to applied excitation.

(a) System identification methodology, (b) Models forms for foam-block and seat occupant system, (c) Modeling and simulation.

Both the seat-occupant and the foam-block systems exhibit nonlinear behavior. In the foam-block system, this comes primarily from the foam behavior. In the seat-occupant system, the behavior of the foam and the geometric constraints on the motion of the occupant both contribute to the nonlinearity. To examine these features of the system in detail, the steady-state response of the systems at different levels of excitation and for different excitation frequencies was examined. The applied base excitation was always a single sinusoidal function that is defined by the peak amplitude of the signal. For example, 
$0.1 \mathrm{~g}$ acceleration means that the peak amplitude value in the signal is $0.1 \mathrm{~g}$. Because of the nonlinear characteristics, the steady-state response is composed of several harmonics (integer multiples of the excitation frequency). The response after the system has reached a steady-state was analyzed in the frequency domain to separate the amplitudes of various harmonic components. Because multiple solutions may be possible at the same excitation frequency, the excitation frequencies were changed in small increments from low to high frequencies and also from high to low frequencies. The frequency responses plotted are the amplitudes of the relative displacements of the riding mass for the foam-block system and that of the hip-joint (H-point) for the seat-occupant system. Note that these results will be different from the frequency responses estimated with more complicated excitations such as a typical seat base vibration measured during a drive on an actual road. In these experiments investigators typically estimate the linear system frequency response that best describes the behavior observed. The nonlinearity is then observed by changes in this best linear explanation of the behavior with the level of the excitation.

\section{Results and Discussion}

The results are discussed in two sections: single-degreeof-freedom foam-block system, and the overall seat-occupant system.

\section{Single-degree-of-freedom foam-block system}

The steady-state response to harmonic base excitation is calculated numerically using time integration. The base acceleration is kept constant and the frequency is varied from 0 to $8 \mathrm{~Hz}$ in steps of $0.25 \mathrm{~Hz}$ away from the resonance peak, and in steps of $0.1 \mathrm{~Hz}$ near the peak. The results are given for four compression levels $(5.5,10,25$ and $46 \%$ compression) corresponding to riding masses of 1.0, 1.5, 1.83 and 2.5 $\mathrm{kg}$ respectively, and for three base acceleration levels $(0.01 \mathrm{~g}$, $0.1 \mathrm{~g}$ and $0.2 \mathrm{~g}$ ). The different compressions in the foam are obtained by specifying different masses for the block on top of the foam. The masses used to obtain the four compression levels are identified in Fig. 6. Due to the nonlinear elastic characteristic of foam, the stiffness of foam varies with compression level (riding mass), and so does the natural frequency of the system. The variation of the natural frequency of the system calculated from the linearized model of the system with compression (steady-state equilibrium position) is shown in Fig. 7, where the values corresponding to the four compression levels used here are clearly marked. Note that the linearized model is obtained from equation (15) by perturbing about the corresponding equilibrium position determined by the riding mass.

The frequency response of the foam-block system for $2.5 \mathrm{~kg}$ riding mass (46\% compression in the foam) and base acceleration values of $0.01 \mathrm{~g}, 0.1 \mathrm{~g}$ and $0.2 \mathrm{~g}$ are shown in Figs. 8(a)-(c) respectively. The first three harmonic components of the response are shown for the $0.1 \mathrm{~g}$ and $0.2 \mathrm{~g}$ cases, as the higher harmonic components are negligible. The damping constant used to obtain the frequency response is based on previous studies ${ }^{27}$ ) where experimental data for steady-state forced response of the foam-block system to base excitation

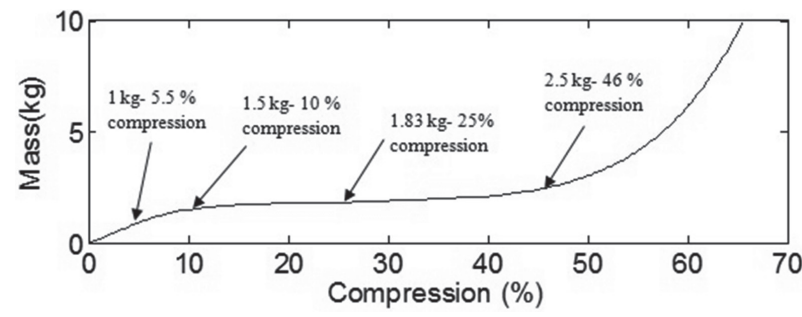

Fig. 6. Mass of block and the corresponding compression in foam for single-degree-of-freedom 'foam-block' system. Also shown are specific values for four different masses riding on foam.

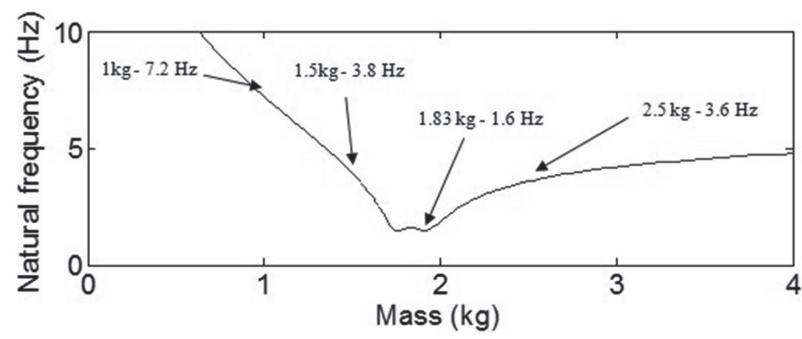

Fig. 7. Natural frequency of the 'foam-block' system as a function of the block mass riding on the foam as calculated from linearized model of foam-block system. Also shown are specific values for four different masses riding on foam.

was used to estimate system model parameters around various compression levels. It is seen from Fig. 8(a) that at low base acceleration level, the response is almost linear. As the acceleration level is increased (Fig. 8(b)), nonlinearity starts influencing the response, with the presence of a superharmonic response at about half the resonance frequency, that is, near $1.5 \mathrm{~Hz}$. This is due to the presence of the even terms in the nonlinear stiffness model of the foam. The nonlinear behavior is more clearly evident in Fig. 8(c) where the base acceleration level is even higher $(0.2 \mathrm{~g})$. The response is much more complex, and the contribution of the second and third harmonic component is significantly higher. It is seen that the resonance peak shifts downwards as the base acceleration increases, from $3.5 \mathrm{~Hz}$ to $2.8 \mathrm{~Hz}$, thus pointing to a softening of foam.

Figsures 9 (a)-(d) depict the frequency response of the foam-block system for a fixed acceleration level $(0.2 \mathrm{~g})$ and various riding masses of $1.0,1.5,1.83$, and $2.5 \mathrm{~kg}(5,10$, 25 and $46 \%$ compression, respectively). The location of the resonance peaks in each of these plots is consistent with the natural frequency of the system calculated from the linearized system model, though affected by the applied acceleration. It is seen from Fig. 8(a) that the resonance peak is closer to the frequency in Fig. 7 for the low acceleration level. The responses in Figs. 9(a)-(d) are for a higher acceleration level, and due to the nonlinear effects, the resonance peak is shifted to lower frequencies except for the case of $1.83 \mathrm{~kg}$ mass, where the resonant frequency increases, thus indicating $a$ local hardening behavior. In addition to the location of the resonance peaks, there are other differences in the responses obtained at different compression levels. For example, the superharmonic response is present markedly in the first har- 
(a) $0.01 \mathrm{~g}$

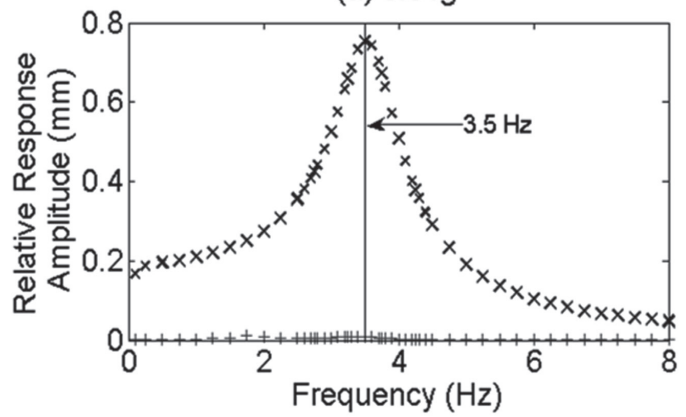

(c) $0.2 \mathrm{~g}$

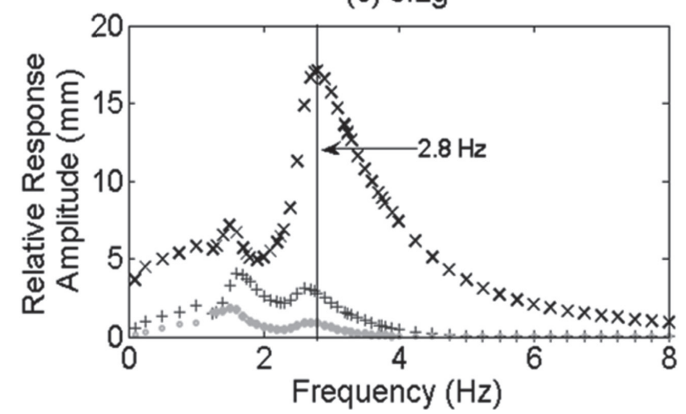

(b) $0.1 \mathrm{~g}$

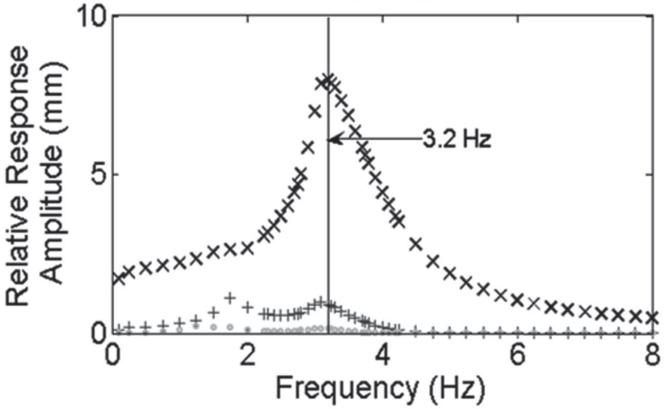

Fig. 8. Frequency response of single-degree-of-freedom system for mass of $\mathbf{2 . 5} \mathbf{~ k g}$ and different base accelerations. (a) $0.01 \mathrm{~g}$, (b) $0.1 \mathrm{~g}$, and (c) $0.2 \mathrm{~g}$. x - First harmonic component, + - Second harmonic component, and o - Third harmonic component.

(a) $1 \mathrm{~kg}$

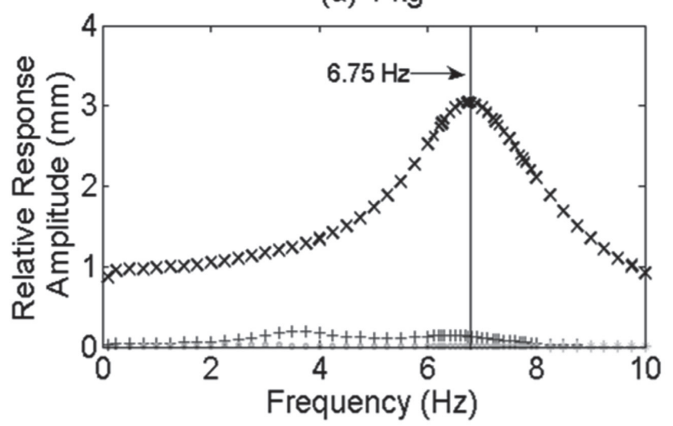

(c) $1.83 \mathrm{~kg}$

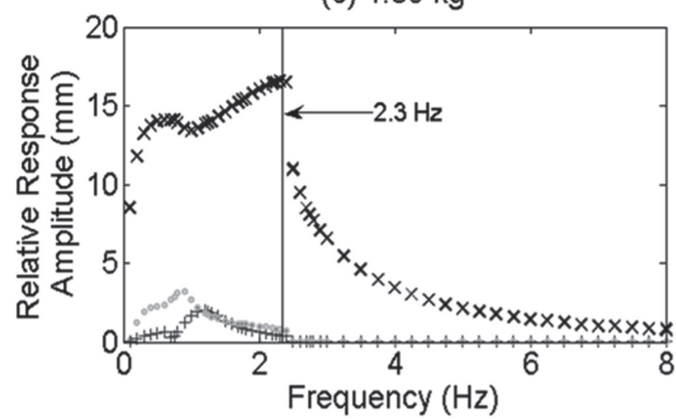

(b) $1.5 \mathrm{~kg}$

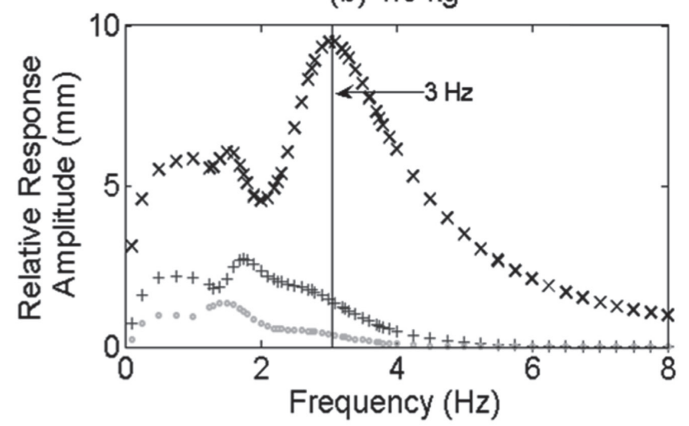

(d) $2.5 \mathrm{~kg}$

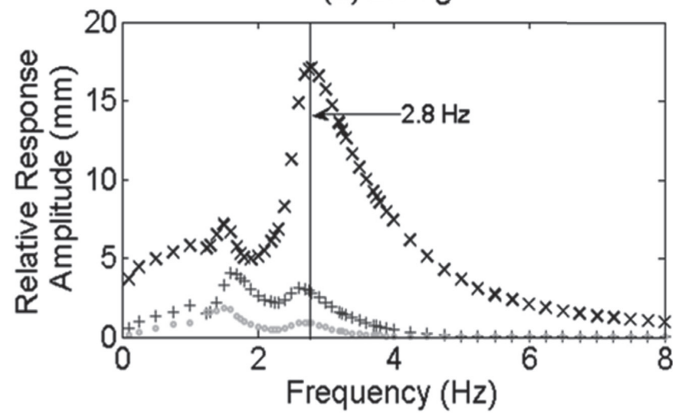

Fig. 9. Frequency response of single-degree-of-freedom system for $0.2 \mathrm{~g}$ base acceleration and different riding masses.

(a) $1 \mathrm{~kg}$, (b) $1.5 \mathrm{~kg}$, (c) $1.83 \mathrm{~kg}$, and (d) $2.5 \mathrm{~kg}$. x - First harmonic component, + - Second harmonic component, and o - Third harmonic component. 


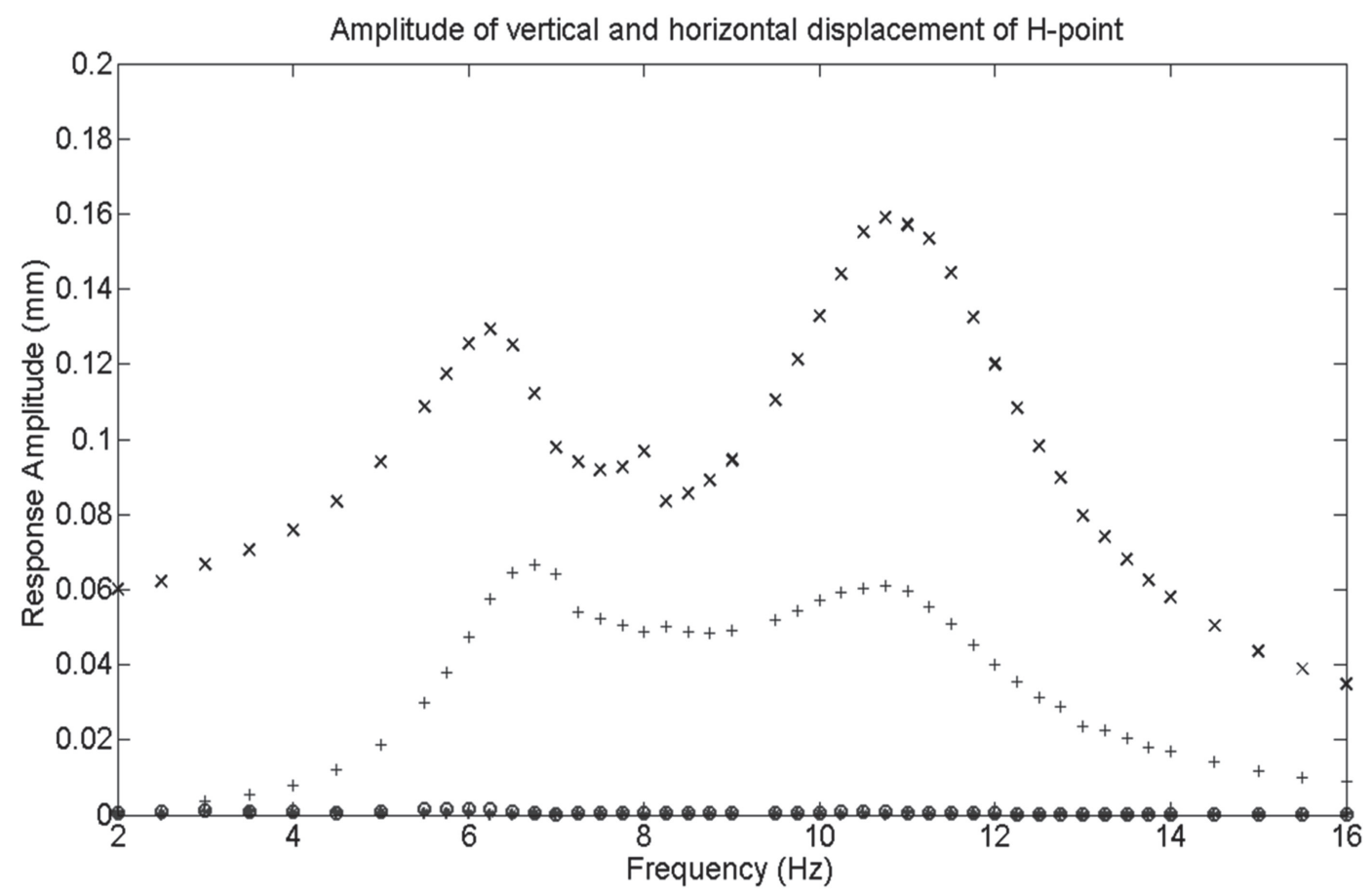

Fig. 10. Amplitudes of vertical and horizontal displacement of the H-point to $0.02 \mathrm{~g}$ base acceleration in vertical direction.

$\mathrm{x}$ - vertical displacement first harmonic component, o - vertical displacement second harmonic component, + - horizontal

(fore-and-aft) displacement first harmonic component, and *- horizontal displacement second harmonic component.

monic component of the response for 1.5 and $2.5 \mathrm{~kg}$ masses, while it is present in the second harmonic component of the response for 1.0 and $1.83 \mathrm{~kg}$ riding masses. The contribution of the third harmonic component also differs with the riding mass (compression level). A peak in the third harmonic component of the response is seen at about $1 / 3$ rd the peak frequency for the $1.83 \mathrm{~kg}$ case (Fig. 9(c)). This peak in the response is due to the presence of the odd terms in the nonlinear elastic foam model. For the other cases, the superharmonic response is present in the third harmonic component. Furthermore, the response amplitude increases with increased compression in the foam, that is, with increase in the riding mass. These results clearly show that the model based on a global nonlinear model of foam is capable of predicting behavior at different compression levels.

After studying the effects of acceleration level and compression level in the single-degree-of-freedom system, the response of the multi-degree-of-freedom seat-occupant system to base excitation is investigated.

\section{Seat-occupant system}

Following the methodology described earlier, the response of the seat-occupant system is obtained in a similar manner to the response of the single-degree-of-freedom foam-mass system. The steady-state response to harmonic base excitation at each frequency is calculated using time integration. The base acceleration is kept constant at $0.02 \mathrm{~g}$, and the frequency is varied from $2 \mathrm{~Hz}$ to $16 \mathrm{~Hz}$ in steps of $0.5 \mathrm{~Hz}$, with a finer frequency resolution used near the peaks. An estimate of the natural frequencies of the system is obtained by studying the response of an undamped version of the system to an impulsive excitation. The mass and inertia properties of the occupant (mannequin) are given in Table 2. The mass as well as the profile of the occupant, and the trim contours in the seat govern the compression in the foam. The damping constants are all equal and taken to be a value of $40 \mathrm{Ns} / \mathrm{m}$. Note that this value is higher than the one used in the single-degreeof-freedom foam-block system and it accounts (in an ad-hoc way) for the friction in the joints of the occupant (mannequin).

The response of the hip joint in vertical and fore-and-aft directions is plotted against excitation frequency in Fig. 10. It is seen that the resonance peaks in the two directions are located at different frequencies. The lower resonance peaks lie at slightly different frequencies $-6.25 \mathrm{~Hz}$ in the vertical direction, and $6.75 \mathrm{~Hz}$ in the fore-and-aft direction. The second resonance peak is observed at the same frequency in both directions, at $10.75 \mathrm{~Hz}$. It is seen that the amplitude of the response in the vertical direction is an order of magnitude larger than the response in the fore-and-aft direction. This is due to the applied excitation being vertical, and in small part due to the seat back being rigid. Due to the small amplitude of acceleration, the contribution of the second and higher harmonic component to the response is also negligible.

\section{Deflection shapes of the seat-occupant system}

The deflection shapes of the system give an idea of the motion of the occupant (mannequin) at the resonant frequencies and can be qualitatively compared with the modes of the mannequin obtained from previous experiments (Kim et $a l^{31)}$ ). The deflection shapes of the overall system are obtained at 
(a) Deflection shape at $6.25 \mathrm{~Hz}$

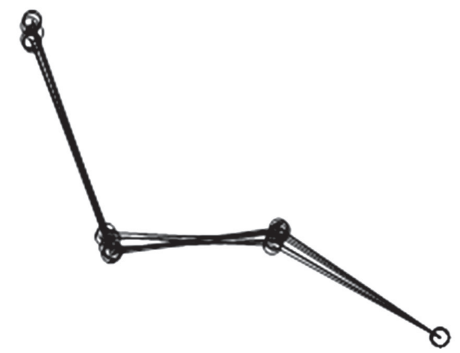

(b) Deflection shape at $6.75 \mathrm{~Hz}$

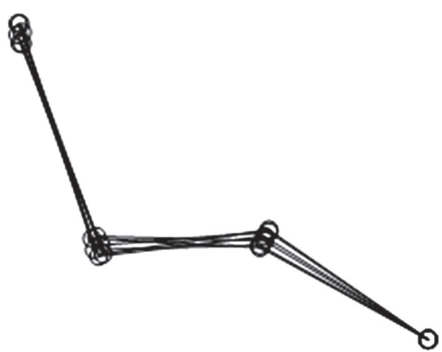

(c) Deflection shape at $10.75 \mathrm{~Hz}$

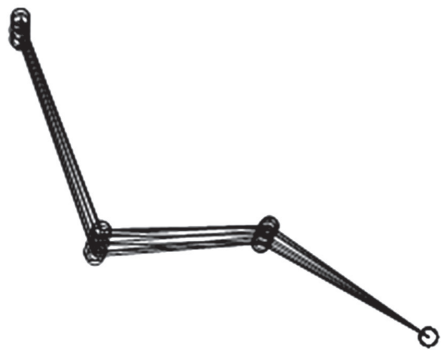

Fig. 11. Operational deflection shapes (ODS) of the seat-occupant system at the resonant frequencies in Fig. 10. (a) $6.25 \mathrm{~Hz}$, (b) $6.75 \mathrm{~Hz}$, and (c) $10.75 \mathrm{~Hz}$

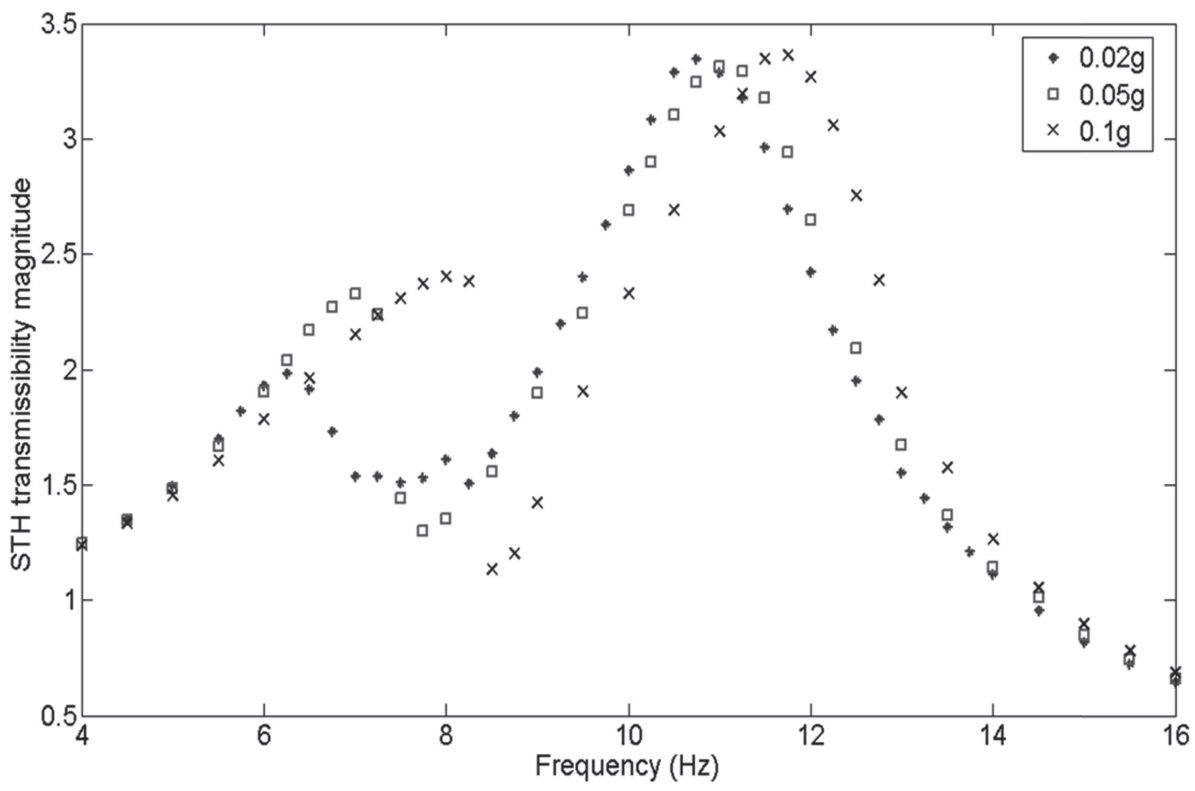

Fig. 12. Seat-to-head transmissibility of the seat-occupant system for $0.02 \mathrm{~g}(*), 0.05 \mathrm{~g}(\square)$, and $0.1 \mathrm{~g}(\mathrm{x})$ base acceleration.

the resonance frequencies seen in Fig. 10 and are given in Figs. 11(a)-(c).

The deflection shape at $10.75 \mathrm{~Hz}$ is seen to contain mainly vertical motion, since the response in the fore-and-aft direction is comparatively much lower in magnitude. The torso, hip, knee and foot have an almost entirely vertical motion, with the hip and knee having maximum displacement. This corresponds to the 'bounce' mode observed by Kim et al. ${ }^{31)}$. The 'pitching' mode observed by Kim et al. ${ }^{31)}$ is not seen explicitly. There is however, a small pitch motion of the torso in the mode at $6.25 \mathrm{~Hz}$. This is due to the absence of a flexible seat back, which does not allow sufficient pitch motion of the occupant. The lower frequency deflection shape in the foreand-aft direction (at $6.75 \mathrm{~Hz}$ ) is similar to the deflection shape at $6.25 \mathrm{~Hz}$ in the vertical direction in that it shows angular displacement of the torso and femur. The displacement of the foot is almost non-existent due to the constraint imposed on the dynamics of the system.

Seat-to-head transmissibility

Seat-to-head (STH) transmissibility ${ }^{2)}$ is a measure that is used to observe the transmission of motion through the body. In this system, the head of the occupant is not modeled. Hence, instead of the motion of the head, the motion of the uppermost point of the torso (or neck) is considered, and the seat-to-head transmissibility is defined as

STH transmissibility $=\frac{A_{\text {neck }}(\omega)}{A_{\text {base }}(\omega)}$

where $A_{\text {neck }}$ is the amplitude of motion of the uppermost point of the torso (or neck) at each excitation frequency, and $A_{\text {base }}$ is the amplitude of seat base displacement at the corresponding excitation frequency. The variation of the magnitude of STH transmissibility with the excitation frequency is given in Fig. 12. Also shown are the STH transmissibility values for $0.05 \mathrm{~g}$ and $0.1 \mathrm{~g}$ base acceleration. All the STHT curves are seen to have two resonance peaks, at around the same frequencies as present in the frequency response of the H-point in the vertical direction (see Fig. 10). Further, the shapes of the curves are also similar to the shape of the vertical frequency response curves. This is expected as the motion of the neck in the vertical direction is a function of the vertical 
displacement of the H-point and the angular displacement of the torso. As the acceleration level increases, the STHT value at the lower resonance peak increases, while the value at higher resonance peak remains nearly constant. As the value of STH transmissibility is greater at the higher resonance peak, it indicates that there is greater transmission of motion at the higher frequencies.

\section{Conclusion and Recommendations for Future Work}

The response of a single-degree-of-freedom foam-block system (incorporating the constitutive model of flexible polyurethane foam) to harmonic base excitation, has been analyzed to understand the effect of various input parameters such as riding mass and level of applied excitation. Furthermore, a multi-body model of the seat-occupant system incorporating the constitutive foam model of has been developed. This model is fairly comprehensive and includes important elements such as the interface forces, foot-floor friction, occupant profile, and most importantly, it takes into account the nonlinear and viscoelastic properties of seating foam. The deflection shapes of the system are found to be comparable to the modes observed from previous experiments. However, the resonant frequencies observed are higher than those generally associated with seated humans. To remedy this, certain modifications to the model are proposed:

(a) An improved model for the seat-occupant interface force needs to be introduced. Currently, a simple model is used for the interfacial force which represents the maximum friction force at the interface.

(b) The seat back should be made flexible by adding a degree of freedom to the model. This will be a more realistic model, and will decrease the resonant frequencies of the system.

This seat-occupant model can also be used to study the effect of the position and posture of seated occupant on the dynamic response of the system. This will be undertaken in the near future, as part of further studies conducted using this model.

\section{Acknowledgements}

The authors gratefully acknowledge support from the National Science Foundation, Dynamic Systems Program, through the grant CMMI-0728101. Dr. Eduardo Misawa is the Program Director. The authors also thank the reviewers for constructive suggestions that have helped improve the work.

\section{References}

1) Griffin MJ (1994) Handbook of human vibration. Academic Press, London.

2) Mansfield NJ (2005) Human response to vibration. CRC Press, Boca Raton.

3) Liang C-C, Chiang C-F (2006) A study on biodynamic models of seated human subjects exposed to vertical vibration. Int J Ind Ergon 36, 869-90.

4) Muskian R, Nash CD (1974) A model for the response of seated humans to sinusoidal displacements of the seat. J Biomech 7, 209-15.

5) Nishiyama $S$ (1993) Development of simulation system on vehicleoccupant dynamic interaction (1st report, Theoretical analysis and system verification). Trans Japan Soc Mech Engs C 59, 3613-21.

6) Nishiyama S (1993) Development of simulation system on vehicle- occupant dynamic interaction (2nd report, Influence of sitting posture on human comfort). Trans Japan Soc Mech Engs C 59, 3622-9.

7) Nishiyama S (1994) Development of simulation system on vehicleoccupant dynamic interaction (3rd report, Influence of parameters of occupant-seat system on human comfort). Trans Japan Soc Mech Engs C 60, 1509-16.

8) Cho Y, Yoon YS (2001) Biomechanical model of human on seat with backrest for evaluating ride quality. Int J Ind Ergon 27, 331-45.

9) Kim TH, Kim YT, Yoon YS (2005) Development of a biomechanical model of the human body in a sitting posture with vibration transmissibility in the vertical direction. Int $\mathbf{J}$ Ind Ergon 35, 817-29.

10) Matsumoto Y, Griffin MJ (2001) Modeling the dynamic mechanisms associated with the principal resonance of the seated human body. Clin Biomech 16, S31-S44.

11) Yoshimura T, Nakai K, Tamaoki G (2005) Multi-body dynamics modeling of seated human body under exposure to whole-body vibration. Ind Health 43, 441-7.

12) Valentini PP, Vita L (2002) DAViD - A multi-body code to simulate a dynamic virtual dummy for vibrational comfort analysis of car occupants. NATO ASI workshop, Prague.

13) Teng TL, Chang FA, Peng CP (2006) Analysis of human body response to vibration using multi-body dynamics method. Proc IMechE 220 Part K: J Multi-body Dyn 220, 190-202.

14) Verver $M$, de Lange $R$, van Hoof $P$, Wismans JSHM (2005) Aspects of seat modeling for seating comfort analysis. Appl Ergon 36, 3342.

15) Verver M, van Hoof J, Oomens C, van de Wouw N, Wismans J (2003) Estimation of spinal loading in vertical vibrations by numerical simulation. Clin Biomech 18, 800-11.

16) Nishiyama $S$, Uesugi $N$, Takeshima $T$, Kano $Y$, Togii H (2000) Research on vibration characteristics between human body and seat, steering wheel, and pedals (Effects of seat position on ride comfort). J Sound Vib 236, 1-21.

17) Rakheja S, Stiharu I, Boileau P-É (2002) Seated occupant apparent mass characteristics under automotive postures and vertical vibration. J Sound Vib 253, 57-75.

18) Liang C-C, Chiang C-F (2008) Modeling of a seated human body exposed to vertical vibrations in various automotive postures. Ind Health 46, 125-37.

19) Wang W, Rakheja S, Boileau P-É (2004) Effects of sitting postures on biodynamic response of seated occupants under vertical vibration. Int J Ind Ergon 34, 289-306.

20) Rakheja S, Stiharu I, Zhang H, Boileau P-É (2006) Seated occupant interactions with seat backrest and pan, and biodynamic responses under vertical vibration. J Sound Vib 298, 651-71.

21) Hinz B, Rützel S, Blüthner R, Menzel G, Wölfel HP, Seidel H (2006) Apparent mass of seated man-First determination with a soft seat and dynamic seat pressure distributions. J Sound Vib 289, 704-24.

22) Patten W, Sha S, Mo C (1998) A vibrational model of open celled polyurethane foam automotive seat cushions. J Sound Vib 217, 145-61.

23) Ippili RK, Davies P, Bajaj AK, Hagenmeyer L (2008) Nonlinear multi-body dynamic modeling of seat-occupant system with polyurethane seat and H-point prediction. Int J Ind Ergon 38, 368-83.

24) Puri $T$ (2004) Integration of polyurethane foam and seat occupant models to predict the settling point of a seat occupant, Master's thesis, Purdue University, School of Mechanical Engineering, West Lafayette, IN 47907.

25) Kolich M (2008) A conceptual framework proposed to formalize the scientific investigation of automobile seat comfort. Appl Ergon 39. $15-27$.

26) White SW, Kim SK, Bajaj AK, Davies P, Showers DK, Liedtke PE (2000) Experimental techniques and identification of nonlinear and viscoelastic properties of flexible polyurethane foam. Nonl Dyn 22, 281-313.

27) Singh R, Davies P, Bajaj AK (2003) Identification of nonlinear and viscoelastic properties of flexible polyurethane foam. Nonl Dyn 34, 319-46.

28) Singh R, Davies P, Bajaj AK (2003) Estimation of the dynamical properties of polyurethane foam through use of Prony series. J Sound Vib 264, 1005-43.

29) Deng R, Davies P, Bajaj AK (2003) Flexible polyurethane foam modeling and viscoelastic parameters identification for automotive seating applications. J Sound Vib 262, 391-417.

30) Greenwood DT (1965) Principles of dynamics. Prentice-Hall, Englewood Cliffs.

31) Kim S, White S, Bajaj AK, Davies P (2003) Simplified models of the vibration of mannequins in car seats. J Sound Vib 264, 49-90. 